\title{
MUSEUS E AFRICANIDADES
}

\author{
Deborah Silva Santos * \\ Universidade de Brasília
}

As coisas, as espécies e os indivíduos provenientes do Continente Africano sempre foram motivo de estranhamento aos olhos do povo europeu. Classificados como bizarros e exóticos representavam o mundo invisível (Pomian, 1984) o “outro" social, não civilizado, mágico e religioso (Gonçalves, 2009). Se no primeiro momento estes objetos foram cobiçados pelos colecionadores no momento subseqüente, nos recém criados museus serviram como objetos/testemunhos para comprovar nas ciências biológicas a "noção da evolução das espécies" e nas ciências humanas a "diferença entre os homens". (Schwarcz, 2005)

Os museus brasileiros foram criados neste contexto e colaborara decisivamente com a divulgação das teorias raciais' no país, com as regras de um progresso humano "único, linear e inquebrantável”. Cada um a seu modo, o Museu Real (Nacional), o Museu Paraense Emílio Goeldi e o Museu Paulista influenciaram as discussões sobre o futuro da nossa nação formada por um povo miscigenado. (Schwarcz,2005; Lopes, 2009)

Apenas no decorrer dos anos de 1920 que a noção de raças humanas foi cedendo lugar a outras noções como a "higiene e cultura" ligada ao desenvolvimento urbano e a industrialização. Coincidentemente, neste mesmo período chega ao fim a "Era dos museus etnográficos" substituídos por outros modelos de instituição. Ainda carregados de negatividade pela sua origem os objetos produzidos pelos afro-brasileiros vão ser preteridos no processo de musealização pela preservação da história dos grandes heróis e dos grandes feitos da história nacional, garantindo a partir de então a preservação da memória cultural do grupo social branco, representante da elite política e econômica brasileira.

Nos dias de hoje, há várias instituições museológicas privadas e públicas brasileiras que ainda optam em guardar, conservar e divulgar a memória dos representantes da elite, desconsiderando a história dos outros grupos formadores da história nacional. Ou quando reconhecem a cultura afro-brasileira, as Africanidades, elas trazem o estigma da escravidão, pois são escolhidas correntes, as gargalhadeiras, chibatas e outros objetos de submissão ao trabalho escravo para retratá-los.

\footnotetext{
*Professora-Assistente do Curso de Museologia da Universidade de Brasília - UnB (e-mail deborahsantos@ unb.br).

1 Evolucionistas sociais, darwinistas sociais, deterministas sociais, poligenistas, craniologia, frenologia .Vide Schwarcz, 2005: I16
} 
O Livro "Museu e Africanidades" busca reverter essa realidade apresentando ações práticas nos acervos, nas exposições e em museus do Rio Grande do Sul. Organizado pela Historiadora Jane Rocha de Mattos ele tem como objetivo superar a invisibilidade da população negra nos museus apresentando-os como agentes históricos.

Ao reunir sete artigos escrito por acadêmicos e intelectuais que segundo Rocha, "tem suas trajetórias marcadas pela reflexão, produção e atuação sobre a temática da afrodescendência" outros lugares, trajetos, memórias e patrimônio vão sendo revelados no Estado e ao mesmo tempo vão possibilitando interpretações teóricas e metodológicas no campo da museologia, como musealização de objetos, salvaguarda do acervo, espaços museais, espaços e experiências museológicas e educação museal.

No artigo As Representações do Negro nos Museus do Rio Grande do Sul são marcadas pela Invisibilidade Simbólica: do "resgate" afro-brasileiro às pesquisas histórico-antropológicas e às visibilidades negras na museologia contemporânea o Antropólogo losvaldyr Carvalho Bittencourt Junior apresenta um "percurso de sensibilização etnográfica" no Museu Antropológico do Rio Grande do Sul (MARS), Museu de Arte do Rio Grande do Sul (MARGS), Museu Joaquim José Felizardo (Museu de Porto Alegre), Museu Júlio de Castilhos e no Memorial do Rio Grande do Sul e aponta como essas instituições museológicas gaúchas são limitadas no seu tradicionalismo e colaboram com a invisibilidade da cultura afro-brasileira nas suas exposições e na tentativa de romper essas determinações e reconhecem as culturas negras na formação da população do estado gaúcho retrata-a enquanto folclórica e estigmatizada pelos objetos de submissão ao trabalho escravo, as correntes, gargalheiras, chibatas e tantos outros objetos de terror. Esses museus desconsideram as

"imagens, memórias, histórias, praticas culturais e inúmeras identidades de matriz africana formas devocionais negras, pesquisas acadêmicas, produção artística e literárias desenvolvidas, por meio da dinâmica histórica e sociocultural, no âmbito territorial das suas comunidades sociais e redes de parentesco, das suas respectivas redes simbólicas de sociabilidades públicas, estão fora do espaço físico e intelectual dos museus tradicionais, quase sempre desconsiderando as interpretações e contribuições dos agentes sociais e culturais negros" (Junior in Mattos, 2013:16)

Junior apresenta formas de superação da invisibilidade negra, como a criação dos museus afro-brasileiros em outras regiões do Brasil e a museologia contemporânea que ao problematizar temáticas do cotidiano amplia o dialogo com os intelectuais orgânicos e os detentores de saberes e produtores de memórias e patrimônio material e imaterial.

O texto de Vinicius Viera de Souza, Artes Visuais de referencia Afro-Brasileira no espaço público de Porto Alegre identifica a cidade como um espaço museológico, um "museu a céu aberto" e busca relacionar a obras de artes visuais de referencias afro-brasileiras e os locais que foram historicamente ocupados pelos negros na cidade. A partir de sete obras instaladas pela cidade, o Monumento a Zumbi dos Palmares no Largo dos Açores; o Monumento à Mãe Oxum na Praia de Ipanema; o busto de João Cândido no Parque da Marinha do Brasil; o Afromosaico no Bairro de Bom Jesus; o Tambor na Praça Brigadeiro Sampaio (antigo largo da Forca); a Pegada Africana localizada na Praça da Alfândega (antigo Largo 
da Quitanda) e o Bará localizado no Mercado Municipal, reflete sobre o rompimento da invisibilidade negra, pois os lugares plasmados na memória coletiva dos negros porto-alegrense passam a ser reconhecidos e publicizados com a instalação das obras de artes visuais de referência afro-brasileira.

$\mathrm{O}$ artigo de Pedro Rubens Vargas, o Museu de Percurso do Negro na perspectiva de seus idealizadores: Os militantes e militantes do Movimento Negro reflete sobre o processo de concepção e implantação do museu do percurso realizado pelos militantes, entidades e organizações do movimento negro porto-alegrense. Ações que enquadradas na luta pelo direito à memória e, portanto de superação do "processo de apagamento paulatino da memória da etnia negra" na cidade de Porto Alegre.

O Museu veio a surgir, portanto, como idea-força, ou melhor, se constitui como ideia-expressão de um movimento de reivindicação por direitos civis e políticos de representação da etnia negra no concerto das memórias dos povos que originaram e fazem Porto Alegre.

As reflexões apresentam também uma ação prática de entendimento entre o poder público e os militantes negros na definição teórica da nova instituição sem precedentes no universo brasileiro, questões que envolveram diferentes campos disciplinares no tratamento do patrimônio.

O texto Antigos Carregadores de Doca: Reflexões acerca das representações negras no Museu Julio de Castilho de Arilson dos Santos Gomes e Roberta Fraga Machado Gomes apresentam as reflexões sobre objeto musealizado, neste caso a fotografia "Antigos Carregadores de Doca” pertencente ao acervo do Museu Julio de Castilho e a ideologia difundida pela instituição museal ao ter o poder de visibilizar ou invisibilizar (silenciar) as identidades. No artigo os autores apresentam de forma clara como a ideologia de um grupo perpassa as ações museológicas sendo capaz de "criar uma memória" que plasmada no objeto será preservada para o futuro. São ações pré-determinadas de formação de acervo, de salvaguarda, de exposição e educação que visavam no caso em tela embranquecer e europeizar a história do Estado do Rio Grande do Sul, desconstituindo as memórias afrodescendentes que estão armazenadas no museu.

O artigo de Maria Ricken de Medeiros e de Nara Witt - Trilhando investigações sobre o quadro de Aurélio Viríssimo de Bittencourt dialoga com o texto anterior ao escolher um objeto museológico para refletir como o museu pode ser um local de produção de conhecimento e de memória. Os autores, a partir do objeto/retrato pintado a óleo identificado como Aurélio Virissimo de Bittencourt, um homem negro, buscam não apenas identificá-lo como homem público no mundo da elite branca e que leva a musealizar a sua figura, como a sua identificação religiosa e destaque no mundo dos negros.

$O$ artigo Representações racializadas de negros nos museus: $O$ que se diz e $o$ que se ensina de autoria de Lisandra Maria Rodrigues Machado e Maria Angélica Zubaran analisa a sala da exposição Período Escravista que integra a exposição de longa duração do Museu Julio de Castilho e constata a necessidade de desconstruir as representações do negro no museu representado enquanto o "outro" homogêneo, sempre escravo, originário de uma África ahistórica e silenciado em suas experiências e saberes negros contemporâneos. As autoras também apresentam um panorama da escassa e recente produção dos estudos que interseccionam a temática étnico-racial e as instituições museológicas no Brasil formada por museólogos, historiadores e antropólogos. 
E por fim o artigo de Giane Vargas Escobar e Ana Luiza Coiro Moraes Rodas de Lembranças do Museu Comunitário Treze de Maio: Comunicação, educação e identidade de mulheres negras reflete sobre uma das experiências comunicacionais dos museus comunitários e ecomuseus que são as rodas de lembranças. $O$ seu objetivo é (re) constituir o patrimônio imaterial e deixar registro da memória vivida por uma comunidade de destino. $A$ importância deste texto evidencia também uma das mais importantes organizações dos afro-brasileiros no Brasil, que são os Clubes Sociais. Aqui em tela a Sociedade Cultural Ferroviária Treze de Maio - "o Treze" da cidade de Santa Maria, Rio Grande do Sul com mais de I 10 anos. Sua trajetória até a transformação em museu comunitário no ano de 2003 é apresentada no artigo pelas autoras, bem como as atividades que vem sendo realizadas na última década.

Ao finalizar, me aventuro a afirmar que "Museu e Africanidades" é daqueles livros que supera o seu objetivo inicial de dar visibilidade a população negra nos museus e assim, atender um público restrito de pesquisadores interessados na produção literária sobre a temática étnico-racial nos museus brasileiros. Pois ao refletir sobre os conceitos teóricos da museologia contemporânea, podemos classificá-lo como uma obra de teoria museológica, ampliando o seu campo de atendimento para estudantes, museólogos e profissionais de museus que anseiam por ações que reconheçam as temáticas de gênero, étnico-raciais e de classe social.

Assim, ao apresentar a desconstrução, reflexão e a revisão dos processos de musealização dos objetos, da elaboração das exposições e atividades educacionais, da salvaguarda e das pesquisas realizadas nos museus tradicionais, e também, a elaboração de novas práticas museais que contam com a participação social e que resultam na formação dos museus comunitários, de percurso e étnicos, as duas experiências museológicas são tratadas como duas formas antagônicas mas que coexistentes, e que partem da mesma base teórica de compreensão do museu como fenômeno e portanto um espaço de disputa e tensão entre a mudança e a permanência, a diferença e a identidade, a memória e a história, o poder e a resistência. (Scheiner,2008)

A nossa intenção não é optar por um dos dois modos de fazer museu, não há ganhadores nem perdedores, o que temos que fazer é garantir e respeitar a visibilidade dos saberes e fazeres de todos os grupos participantes das sociedades multirraciais e multiculturais.

Obra: MATTOS, Jane Rocha (org). Museus e Africanidades. Porto Alegre,RS: Edições Museu Julio de Castilhos, 2013.

\section{Outras Referências}

GONÇALVES, José Reginaldo Santos. O patrimônio como categoria de pensamento. In:ABREU, Regina; CHAGAS, Mário (orgs). Memória e Patrimônio: ensaios contemporâneos. Rio de Janeiro: Lamparina, 2009 - 2a. ed. p.25-33.

LOPES, Maria Margaret. O Brasil descobre a pesquisa científica: os museus e as ciências naturais no século XIX. São Paulo;Aderaldo \& Rochschild; Brasília, DF: Ed. Unb, 2009

POMIAN, Krzysztof. Coleção. In: Enciclopédia Eunadi, v. I. Lisboa, Imprensa Nacional - Casa da Moeda, 1984 
SCHEINER, Teresa Cristina. O Museu como Processo. In: Bittencourt, José Neves (org). Cadernos de Diretrizes Museológicas 2. Bh, SECMG, Superintendencia de Museus,2008. http://www.cultura.mg.gov.br/files/museus/I caderno_diretrizes_museologicas_2.pdf

SCHWARCZ, Lillia K. Moritz. A "Era dos Museus de Etnografia" no Brasil: o Museu Paulista, o Museu Nacional e o Museu Paraense em finais do século XIX. In: Museus: dos gabinetes de curiosidades à museologia moderna. Belo Horizonte/ Brasília:Argumentum/CNPq, 2005

Resenha recebiba em maio de 20/4.Aprovado em junho de 2014 
292

늠

चै

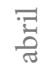

을 